Abstract THU0141 - Table 1. BMD values and changes in BMD during four years of treatment

\begin{tabular}{|c|c|c|c|c|c|c|c|c|c|}
\hline & \multicolumn{3}{|c|}{ COBRA-Light } & \multicolumn{3}{|c|}{ COBRA } & \multicolumn{3}{|c|}{ GEE analyses } \\
\hline & \multirow[t]{2}{*}{ Baseline } & \multicolumn{2}{|c|}{ Bone Loss } & \multirow[t]{2}{*}{ Baseline } & \multicolumn{2}{|c|}{ Bone Loss } & \multirow{2}{*}{$\begin{array}{c}\text { Mean } \\
\text { difference }\end{array}$} & \multirow[t]{2}{*}{$\mathrm{Cl}$} & \multirow[t]{2}{*}{$P$} \\
\hline & & Absolute & $\begin{array}{c}\% \text { of } \\
\text { baseline }\end{array}$ & & Absolute & $\begin{array}{c}\% \text { of } \\
\text { baseline }\end{array}$ & & & \\
\hline \multirow[t]{3}{*}{$\begin{array}{l}\text { Lumbar } \\
\text { Spine }\end{array}$} & $\begin{array}{c}1.10 \\
(0.15)\end{array}$ & $\begin{array}{l}-0.01 \\
(0.08)\end{array}$ & -0.5 & $\begin{array}{c}1.12 \\
(0.18)\end{array}$ & $\begin{array}{l}-0.01 \\
(0.08)\end{array}$ & -1.0 & -0.01 & $\begin{array}{c}-0.03- \\
0.02\end{array}$ & 0.56 \\
\hline & & & & & & & $-0.01^{*}$ & $\begin{array}{c}-0.03- \\
0.02\end{array}$ & 0.56 \\
\hline & & & & & & & $-0.01^{* *}$ & $\begin{array}{c}-0.03- \\
0.02\end{array}$ & 0.59 \\
\hline \multirow[t]{3}{*}{ Total Hip } & $\begin{array}{c}0.96 \\
(0.13)\end{array}$ & $\begin{array}{l}-0.03 \\
(0.05)\end{array}$ & -3.3 & $\begin{array}{c}0.95 \\
(0.15)\end{array}$ & $\begin{array}{l}-0.02 \\
(0.05)\end{array}$ & -1.7 & -0.01 & $\begin{array}{l}-0.02- \\
0.00\end{array}$ & $0.05+$ \\
\hline & & & & & & & $-0.01^{*}$ & $\begin{array}{l}-0.02- \\
0.00\end{array}$ & $0.05+$ \\
\hline & & & & & & & $-0.01^{\star *}$ & $\begin{array}{c}-0.03- \\
0.00\end{array}$ & $0.02+$ \\
\hline \multirow[t]{3}{*}{$\begin{array}{l}\text { Femoral } \\
\text { Neck }\end{array}$} & $\begin{array}{c}0.88 \\
(0.12)\end{array}$ & $\begin{array}{l}-0.03 \\
(0.05)\end{array}$ & -3.7 & $\begin{array}{c}0.90 \\
(0.16)\end{array}$ & $\begin{array}{l}-0.03 \\
(0.06)\end{array}$ & -3.0 & -0.01 & $\begin{array}{c}-0.04- \\
0.02\end{array}$ & 0.38 \\
\hline & & & & & & & $-0.01^{*}$ & $\begin{array}{c}-0.04- \\
0.01\end{array}$ & 0.37 \\
\hline & & & & & & & $-0.01^{* *}$ & $\begin{array}{c}-0.04- \\
0.01\end{array}$ & 0.29 \\
\hline
\end{tabular}

In the COBRA group, these numbers were $10 \%, 3.2 \mathrm{~g}(2.5 ; 6.2)$ and $49 \%$, respectively. At the lumbar spine, both groups showed no significant decline in BMD over four years and no difference between treatment groups in BMD change (table 1). At the hips, $1.7 \%$ to $3.7 \%$ BMD loss over four years was found with slightly but significantly more loss in the COBRA-light group (table 1).

Outcomes are mean (SD) unless stated otherwise. BMD in $\mathrm{g} / \mathrm{cm}^{2}$.+Significant diffference between COBRA-light and COBRA on average over time. *Adjusted for bisphosphonate usage (yes vs no). ${ }^{* *}$ Adjusted for bisphosphonate usage (yes vs no), cumulative prednisolone usage, age, gender and disease activity based on DAS44 (DAS44 $<1.6$ in remission vs DAS44 $>1.6$ not). $\mathrm{Cl}$, confidence interval; GEE, Generalised Estimating Equations; T4, measurement after four years; SD, Standard Deviation.

Conclusions: In modern treat-to-target management of RA, including bone surveillance, a high starting dose of prednisolone, either 30 or $60 \mathrm{mg} / \mathrm{day}$, was not associated with a dramatically increased bone loss at the lumbar spine, and minor losses at the hip over four years.

Disclosure of Interest: M. Lucassen: None declared, M. ter Wee: None declared, D. den Uyl: None declared, N. Konijn: None declared, M. Nurmohamed Speakers bureau: Janssen, Roche, MSD, Pfizer, Eli Lilly, BMS and Abbvie, D. van Schaardenburg: None declared, P. Kerstens: None declared, I. Bultink Speakers bureau: Lilly Netherlands, MSD, Amgen BV, UCB Pharma BV, Sanofi Genzyme BV, L. Van Tuyl: None declared, M. Boers Consultant for: Pfizer, Union Chimique Belge and Teva, W. Lems Grant/research support from: Pfizer, Speakers bureau: Pfizer, Abbvie and Roche

DOI: 10.1136/annrheumdis-2018-eular.2826

\section{THU0142 THE PROGNOSIS OF HEART FAILURE IN PATIENTS WITH RHEUMATOID ARTHRITIS}

Y. Meissner $^{1}$, M. Schäfer ${ }^{1}$, B. Manger ${ }^{2}$, M. Zänker ${ }^{3}$, W. Ochs ${ }^{4}$, J. Listing ${ }^{1}$, A. Strangfeld ${ }^{1} .{ }^{1}$ German Rheumatism Research Center, Berlin; ${ }^{2}$ Scientific Advisory Board, Erlangen; ${ }^{3}$ Rheumatologist, Bernau; ${ }^{4}$ Rheumatologist, Bayreuth, Germany

Background: Heart failure (HF) is a condition with high rates of hospital admission and mortality. The impact of rheumatoid arthritis (RA) and its treatment on the prognosis of prevalent HF has been insufficiently studied.

Objectives: To evaluate deterioration of $\mathrm{HF}$ and mortality in patients with RA and concomitant HF.

Methods: The prospectively followed cohort of the German register RABBIT continuously includes RA patients with a new start of a DMARD after at least one csDMARD failure. Among all patients enrolled between 05/2001 and 10/2017 $(n=15,037)$ patients with prevalent HF were selected $(n=393)$. HF patients were followed until their end of observation or death. Deterioration of HF requiring hospital admission, and death were analysed as composite outcome. Incidence rates (IR) were calculated for current treatment at time of event (9 months risk window after last infusion of rituximab). Generalised estimation equations (GEE) were used to investigate risk factors for the composite outcome. To avoid uncertainties when allocating therapies, only treatment episodes $>6$ months were included in the GEE analysis. Missing values (DAS28, CRP, physical function) were addressed by multiple imputations.

Results: Of the 393 patients with prevalent HF and 1490 patient years (PY) of follow-up, a total of 131 patients had at least one outcome (19 HF deteriorations, 123 deaths). Infections (30\%) and cardiovascular events (25\%) were most frequently reported as causes of death. The mean time until deterioration/death was 30/35 months. At baseline, patients with an event were older (69 vs. 67 years), more often male (43 vs. $32 \%$ ), rheumatoid factor positive ( 80 vs. $74 \%$ ), had higher CRP-values (39 vs. $23 \mathrm{mg} / \mathrm{L}$ ) and a worse $\mathrm{FFbH}$ (\% of physical function: 43 vs. 50 ) than patients without event. All HF patients had high numbers of comorbidities (mean of 7/6 in patients with/without event).

Crude IR were highest in patients under csDMARD only exposure (figure 1). IR were similar during the first 3 or 6 months after start of treatment and thereafter (data not shown). Biologic treatment was not associated with the outcome (table 1). Male gender, higher age, a higher glucocorticoid dose, worse physical function and elevated CRP under treatment were significantly associated with hospitalisation due to HF or a fatal outcome.

Abstract THU0142 - Table 1. Adjusted relative risk of HF deterioration or death in RA patients with underlying HF. CRP, FFbH and glucocorticoid doses were averaged for the time of a therapy episode.

\begin{tabular}{lccc}
\hline & Relative risk & 95\% Confidence interval \\
\hline csDMARD & Ref. & & \\
\hline TNF inhibitors & 0.7 & 0.4 & 1.3 \\
Abatacept & 0.8 & 0.3 & 2.3 \\
Rituximab & 0.5 & 0.2 & 1.1 \\
Tocilizumab & 0.9 & 0.3 & 2.6 \\
Baseline age per 5 years & 1.3 & 1.1 & 1.5 \\
Male vs. female & 2.4 & 1.4 & 3.9 \\
CRP per 5 mg/L & 1.03 & 1.004 & 1.1 \\
\% of physical function per 10 points & 0.9 & 0.8 & 0.999 \\
Sum of baseline comorbidities & 1.1 & 0.96 & 1.3 \\
Glucocorticoids per 5 mg/d & 1.4 & 1.03 & 1.8 \\
Smoker vs non-smoker & 1.7 & 1.02 & 3.0
\end{tabular}

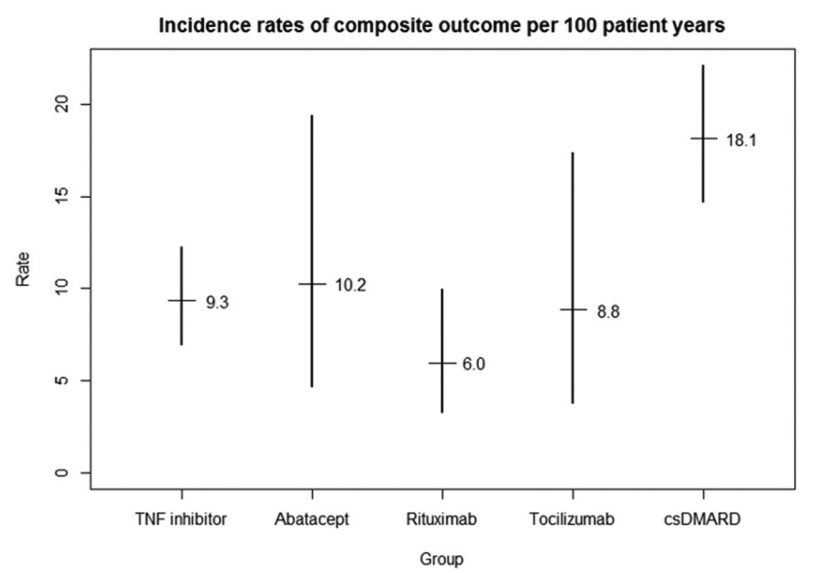

Abstract THU0142 - Figure 1. Incidence rates of composite outcome per 100 patient years 
Conclusions: Patients with RA and HF have an unfavourable prognosis. One third of them were hospitalised for HF or died during follow-up. In addition to patient characteristics, smoking, insufficiently controlled inflammation and treatment with glucocorticoids significantly increased the risk of hospitalisation or death.

Acknowledgements: RABBIT is supported by a joint, unconditional grant from AbbVie, Bristol-Myers Squibb, Celltrion, Hexal, Lilly, MSD Sharp and Dohme, Pfizer, Roche, Samsung Bioepis, Sanofi-Aventis und UCB.

Disclosure of Interest: Y. Meissner Speakers bureau: Pfizer, M. Schäfer: None declared, B. Manger: None declared, M. Zänker Speakers bureau: Celgene, MSD, Roche, W. Ochs: None declared, J. Listing: None declared, A. Strangfeld Speakers bureau: AbbVie, BMS, Lilly, MSD, Pfizer, Roche, UCB DOI: 10.1136/annrheumdis-2018-eular.3979

A. Blanken ${ }^{1}$, R. Agca ${ }^{1}$, A. Voskuijl1, R. Boellaard², C. van der Laken¹, M. Nurmohamed ${ }^{1} .{ }^{1}$ Amsterdam Rheumatology and immunology Center, Reade, VUmc and AMC; ${ }^{2}$ Radiology and Nuclear Medicine, VU University Medical Centre, Amsterdam, Netherlands

Background: Patients with rheumatoid arthritis (RA) have an elevated cardiovascular (CV) disease risk, mostly explained by both an increased prevalence of traditional $\mathrm{CV}$ risk factors and the presence of systemic inflammation that accelerates atherosclerosis. There is accumulating evidence that anti-inflammatory treatment for RA reduces this $\mathrm{CV}$ risk. A non-invasive tool for detecting vascular wall inflammation in atherosclerosis is 18F-Fluorodeoxyglucose-Positron Emission Tomography/Computed Tomography (18F-FDG-PET/CT)

Objectives: To study the effect of anti-inflammatory treatment with methotrexate (MTX) or adalimumab on vascular wall inflammation in RA assessed by $18 \mathrm{~F}$ FDG-PET/CT.

Methods: 18F-FDG-PET/CT was done in patients with active early RA starting MTX $(n=25)$ and active established RA starting adalimumab $(n=24)$ before and after 6 months of therapy, and in osteoarthritis controls (OA; $n=29)$. 18F-FDG uptake in arterial wall was determined by standardised uptake values (SUV). Volumes of interest covering the arterial segment with the highest 18F-FDG were defined to derive the maximum SUV (SUVmax) in the ascending, descending and abdominal aorta and the aortic arch. Global arterial uptake was estimated using the mean SUVmax of the four arterial segments.

Results: Mean age was $65 \pm 9$ for early RA, $61 \pm 7$ for established RA and $63 \pm 5$ years for OA controls. Median disease duration was 2.1 (interquartile range (IQR) 1.3-3.3) weeks for early RA and 6.9 (IQR 1.8-13.9) years for established RA. DAS28 was $4.9 \pm 1.0$ and $4.4 \pm 1.0$ at baseline and declined to $3.1 \pm 1.3$ and $2.8 \pm 1.4$ after 6 months therapy, respectively.

At baseline mean SUVmax was $1.86 \pm 0.38$ for early RA, $1.68 \pm 0.43$ for established RA and $1.56 \pm 0.41$ for OA controles. SUVmax tended to decline more in early RA patients when compared to established RA $(1.86 \pm 0.38$ to $1.79 \pm 0.43(-3.7 \%)$ and $1.68 \pm 0.43$ to $1.63 \pm 0.43(-3.0 \%)$, respectively). SUVmax in most arterial segments declined after 6 months of therapy (table 1). The most prominent decline in SUV-

Conclusions: A decline in global arterial SUVmax and in most of arterial segments was found in both early and established RA patients after 6 months of MTX and/or adalimumab, suggesting that anti-inflammatory therapy with either MTX and/or adalimumab decreases arterial wall inflammation and thus CV risk in RA.

Disclosure of Interest: None declared

DOI: 10.1136/annrheumdis-2018-eular.5660

\section{THU0143 VASCULAR WALL INFLAMATION IN RHEUMATOID ARTHRITIS PATIENTS DECREASES AFTER 6 MONTHS OF ANTI-INFLAMMATORY THERAPY WITH METHOTREXATE OR ADALIMUMAB AS MEASURED BY 18F-FDG-PET/CT} max was in de abdominal aorta in established RA patients $(-9.8 \%)$.

\section{THU0144}

PERFORMANCE OF THE ERS-RA CARDIOVASCULAR RISK PREDICTION TOOL: EXTERNAL VALIDATION IN A LARGE SWEDISH COHORT WITH RA

L. Ljung ${ }^{1,2}$, P. Ueda ${ }^{2}$, K.P. Liao ${ }^{3}$, J.D. Greenberg ${ }^{4,5}$, C.J. Etzel ${ }^{5}$, D.H. Solomon ${ }^{3}$, J. Askling ${ }^{2} .{ }^{1}$ Umeå University, Umeå; ${ }^{2}$ Karolinska Institutet, Stockholm, Sweden; ${ }^{3}$ Brigham and Women's Hospital, Boston, MA; ${ }^{4}$ New York University School of Medicine, New York; ${ }^{5}$ Corrona LLC, Waltham, MA, USA

Background: Risk prediction tools developed for the general population tend to underestimate the risk of cardiovascular $(C V)$ disease in patients with $\mathrm{RA}^{1}$. An accurate and RA-specific CV risk prediction tool would ideally be integrated as a routine part of clinical practice in rheumatology, to identify patients with increased $\mathrm{CV}$ risks. For example, 10 year CV risks above $7.5 \%$, or $10 \%$, could warrant specific preventive measures ${ }^{2,3}$. The ERS-RA was derived and internally validated in the US Corrona RA registry ${ }^{4}$. ERS-RA estimates the 10 year $\mathrm{CV}$ risk using dichotomous clinical variables, and includes variables on RA disease severity and activity.

Objectives: To assess the external validity of the ERS-RA in Swedish cohorts of patients with RA, with focus on the risk intervals of main clinical interest.

Methods: We identified two cohorts of patients with RA: (i) an "incident 2006 cohort" with RA patients in the Swedish Rheumatology Register from Jan 1, 2006 - Dec 31, 2011 who were also in the EIRA case-control study ( $n=2047$, mean age $55 \pm 13$ years, $72 \%$ women), and (ii) a "prevalent 2012 cohort" that included all RA patients in the Swedish Rheumatology Register between Jan 1, 2012 - Dec 31 2015 ( $n=14485$, mean age $61 \pm 14$ years, $74 \%$ women). The 10 year $C V$ risk was estimated using ERS-RA. Patients with a history of myocardial infarction or stroke were excluded. All patients were followed for the first of any of the following: a CV event (myocardial infarction, stroke, cardiovascular death), death, 10 years of follow-up, or Dec 31, 2015. Ten-year CV rates were expressed using the KaplanMeier method. In the prevalent 2012 cohort, the 10 year event rates were extrapolated from the observed (maximally four-year) rates. ${ }^{5}$ The C-statistic was estimated to assess discrimination. A measure of model calibration, the observed event rates were compared with the mean predicted 10 year risks.

Results: The C-statistic was 0.75 for both cohorts. Most patients had an estimated $\mathrm{CV}$ risk $<5 \%$ or of $>10 \%$ (See table 1). An accurate risk prediction was observed for estimated risks in the intervals $<5 \%$, and 5.0 to $<7.5 \%$. ERS-RA underestimated risk in the interval 7.5 to $<10 \%$ (see table 1 and figure 1 ).

Abstract THU0144 - table 1. and figure 1. Comparisons of the mean estimated and the observed 10-year CV risks within groups of estimated risk levels.

\begin{tabular}{|c|c|c|c|c|c|}
\hline & $\begin{array}{c}\text { Groups of } \\
\text { estimated } \\
10 \text { year } \\
\text { risk }\end{array}$ & $\begin{array}{c}\mathrm{N} \\
\text { patients } \\
(\%)\end{array}$ & $\begin{array}{c}\text { Mean } \\
\text { estimated } \\
10 \text { year } \\
\text { risk (\%) }\end{array}$ & $\begin{array}{c}\text { Observed } \\
10 \text { year } \\
\text { rate }(\%)\end{array}$ & $\begin{array}{l}\text { Difference Observed rate } \\
\text { - Mean estimated risk }\end{array}$ \\
\hline Incident & $<5 \%$ & $884(48)$ & 2.5 & 2.3 & -0.2 \\
\hline \multirow{4}{*}{$\begin{array}{l}2006 \\
\text { Cohort }\end{array}$} & 5.0 & $282(15)$ & 6.2 & 5.7 & -0.5 \\
\hline & to $<7.5 \%$ & & & & \\
\hline & $\begin{array}{l}7.5 \\
\text { to }<10 \%\end{array}$ & $43(2)$ & 8.6 & 13.4 & 4.8 \\
\hline & $\geq 10.0 \%$ & $638(35)$ & 18.3 & 18.3 & 0 \\
\hline $\begin{array}{l}\text { Prevalent } \\
2012\end{array}$ & $<5 \%$ & $\begin{array}{l}4691 \\
(32)\end{array}$ & 2.7 & 1.9 & -0.8 \\
\hline \multirow[t]{3}{*}{ Cohort } & $\begin{array}{l}5.0 \\
\text { to }<7.5 \%\end{array}$ & $\begin{array}{c}1604 \\
(11)\end{array}$ & 6.2 & 4.0 & -2.2 \\
\hline & $\begin{array}{l}7.5 \\
\text { to }<10 \%\end{array}$ & $\begin{array}{l}1485 \\
(10)\end{array}$ & 8.6 & 12.0 & 3.4 \\
\hline & $\geq 10.0 \%$ & $\begin{array}{c}6705 \\
(46)\end{array}$ & 22.2 & 24.5 & 2.3 \\
\hline
\end{tabular}

Abstract THU0143 - Table 1. Arterial 18F-FDG uptake in RA patients before and after 6 months of therapy

\begin{tabular}{|c|c|c|c|c|c|c|c|}
\hline & \multirow{2}{*}{$\begin{array}{c}\text { OA } \\
\text { Baseline }\end{array}$} & \multicolumn{3}{|c|}{ Early RA } & \multicolumn{3}{|c|}{ Established RA } \\
\hline & & Baseline & $\begin{array}{c}6 \text { months } \\
\text { MTX }\end{array}$ & & Baseline & $\begin{array}{c}6 \text { months } \\
\text { adalimumab }\end{array}$ & \\
\hline SUVmax ascending aorta & $1.55 \pm 0.44$ & $1.82 \pm 0.38$ & $1.77 \pm 0.38$ & $-2.7 \%$ & $1.69 \pm 0.61$ & $1.60 \pm 0.44$ & $-5.3 \%$ \\
\hline SUVmax descending aorta & $1.57 \pm 0.42$ & $1.93 \pm 0.53$ & $1.81 \pm 0.47$ & $-6.2 \%$ & $1.65 \pm 0.39$ & $1.71 \pm 0.47$ & $+3.6 \%$ \\
\hline SUVmax abdominal aorta & $1.62 \pm 0.43$ & $1.84 \pm 0.44$ & $1.81 \pm 0.58$ & $-1.6 \%$ & $1.73 \pm 0.61$ & $1.56 \pm 0.45$ & $-9.8 \%$ \\
\hline SUVmax aortic arch & $1.51 \pm 0.48$ & $1.85 \pm 0.48$ & $1.76 \pm 0.45$ & $-4.9 \%$ & $1.66 \pm 0.40$ & $1.64 \pm 0.59$ & $-1.2 \%$ \\
\hline $\begin{array}{l}\text { Mean SUVmax over } 4 \\
\text { segments }\end{array}$ & $1.56 \pm 0.42$ & $1.86 \pm 0.38$ & $1.79 \pm 0.43$ & $-3.7 \%$ & $1.68 \pm 0.43$ & $1.63 \pm 0.43$ & $-3.0 \%$ \\
\hline
\end{tabular}

